\title{
Chemical composition and antifungal activity of the essential oils of Lavandula viridis L'Hér.
}

\author{
Mónica Zuzarte, ${ }^{1,2}$ Maria José Gonçalves, ${ }^{1}$ Carlos Cavaleiro, ${ }^{1}$ \\ Jorge Canhoto, ${ }^{2}$ Luís Vale-Silva, ${ }^{3}$ Maria João Silva, ${ }^{3}$ Eugénia Pinto ${ }^{3}$ \\ and Lígia Salgueiro ${ }^{1}$ \\ ${ }^{1}$ Center of Pharmaceutical Studies, Faculty of Pharmacy, Health Science Campus, University of \\ Coimbra, Azinhaga de S. Comba, 3000-354 Coimbra, Portugal \\ ${ }^{2}$ Center of Pharmaceutical Studies, Department of Life Sciences, University of Coimbra, Ap. 3046, \\ 3001-401 Coimbra, Portugal \\ ${ }^{3}$ Microbiology Service/CEQUIMED, Faculty of Pharmacy, University of Porto, Rua Aníbal Cunha \\ 164, 4050-047 Porto, Portugal
}

Correspondence

Lígia Salgueiro

ligia@ff.uc.pt

Received 31 October 2010

Accepted 19 January 2011

\begin{abstract}
In the present work we report for what we believe to be the first time the antifungal activity and mechanism of action of the essential oils of Lavandula viridis from Portugal. The essential oils were isolated by hydrodistillation and analysed by GC and GC/MS. The MIC and the minimal lethal concentration (MLC) of the essential oil and its major compounds were determined against several pathogenic fungi. The influence of subinhibitory concentrations of the essential oil on the dimorphic transition in Candida albicans was also studied, as well as propidium iodide and FUN-1 staining of Candida albicans cells by flow cytometry following short treatments with the essential oil. The oils were characterized by a high content of oxygen-containing monoterpenes, with 1,8-cineole being the main constituent. Monoterpene hydrocarbons were present at lower concentrations. According to the determined MIC and MLC values, the dermatophytes and Cryptococcus neoformans were the most sensitive fungi (MIC and MLC values ranging from 0.32 to $0.64 \mu \mathrm{ml}^{-1}$ ), followed by Candida species (at $0.64-2.5 \mu \mathrm{ml}^{-1}$ ). For most of these strains, MICs were equivalent to MLCs, indicating a fungicidal effect of the essential oil. The oil was further shown to completely inhibit filamentation in Candida albicans at concentrations well below the respective MICs (as low as MIC/16). Flow cytometry results suggested a mechanism of action ultimately leading to cytoplasmic membrane disruption and cell death. Our results show that L. viridis essential oils may be useful in the clinical treatment of fungal diseases, particularly dermatophytosis and candidosis, although clinical trials are required to evaluate the practical relevance of our in vitro research.
\end{abstract}

\section{INTRODUCTION}

Over the last few decades, there has been an increase in the number of serious human infections in immunocompromised patients caused by fungi (Pfaller et al., 2006). The range of severity of these infections is a consequence of the host reaction to the metabolic products produced by fungi, the virulence of the infecting strain, the site of infection and also environmental factors (Romani, 2007). Nowadays, the increasing impact of these infections, the limitations encountered in their treatment (e.g. resistance, side-effects and high toxicity) and the rising overprescription and overuse of conventional antifungals (Pérez-Parra et al., 2009; Ferris et al., 2002) all stimulate a search for alternative natural drugs.

Abbreviations: MLC, minimal lethal concentration; Pl, propidium iodide.
In recent years, research on aromatic plants, and particularly their essential oils, has attracted many investigators. Essential oils have traditionally been used for centuries for their antifungal properties (Ríos \& Recio, 2005). More recently, several studies have confirmed the huge potential of these natural products as antifungal agents (Bakkali et al., 2008; Cavaleiro et al., 2006; Pina-Vaz et al., 2004; Pinto et al., 2006; Zuzarte et al., 2009). Therefore, it is not surprising that essential oils are one of the most promising groups of natural products for the development of broad-spectrum, safer and cheaper antifungal agents.

The genus Lavandula provides valuable essential oils mainly for the food (flavouring), perfumery and cosmetic industries, and is also very popular in aromatherapy. However, many other applications can be foreseen, as 
suggested in several reports on the biological activity of this genus. Lavandula oils have been reported to have sedative and antispasmodic properties (Cavanagh \& Wilkinson, 2002) as well as acaricidal (Perrucci et al., 1996), antibacterial (e.g. Dadalioğlu \& Evrendilek, 2004; Moon et al., 2006), antifungal (e.g. Angioni et al., 2006; Zuzarte et al., 2009) and antioxidant (Matos et al., 2009) activities. More recently, application as a biopesticide has also been suggested by González-Coloma et al. (2006).

Lavandula viridis L'Hér. is a highly aromatic shrub endemic to the south Iberian Peninsula. It is commonly known as green or white lavender due to its white flowers and green floral bracts, which are very distinct from those of the other lavenders. Dried leaves of L. viridis are used with medical applications in Madeira, Portugal (Upson \& Andrews, 2004).

As part of our ongoing study on the valorization of Portuguese lavenders, we now report the chemical composition, antifungal activity and mechanism of action of $L$. viridis essential oils. As far as we know, this is the first report on the antifungal activity of this species.

\section{METHODS}

Plant material. Aerial parts of two samples of L. viridis were collected from field-growing plants in the flowering stage in the south of Portugal (A, Barranco do Velho region; B, Salir region). Voucher specimens were deposited at the herbarium of the Department of Life Sciences of the University of Coimbra (COI).

Essential oil isolation and analysis. The essential oils from airdried plant material were isolated by hydrodistillation for $3 \mathrm{~h}$, using a Clevenger-type apparatus according to the European Pharmacopoeia (Council of Europe, 1997). The oils were preserved in a sealed vial at $4{ }^{\circ} \mathrm{C}$. Oil analyses were carried out by both GC and GC/MS using fused silica capillary columns with two different stationary phases (SPB-1 and SupelcoWax-10) as previously reported (Cavaleiro et al., 2004).

The volatile compounds were identified by both their retention indices and their mass spectra. Retention indices, calculated by linear interpolation relative to retention times of a series of $n$-alkanes, were compared with those of authenticated samples from the database of the Laboratory of Pharmacognosy, Faculty of Pharmacy, University of Coimbra. Mass spectra were compared with reference spectra from a home-made library or from literature data (Adams, 1995; Joulain \& König, 1998). Relative amounts of individual components were calculated based on GC peak areas without flame ionization detector response factor correction.

Pure and reference compounds. Authentic samples of 1,8-cineole (Merck; 99.5\% purity), $\alpha$-pinene (Fluka; $99.0 \%$ purity), linalool (Aldrich; $99.0 \%$ purity) and camphor (Extrasynthese) were used.

Fluconazole was kindly provided by Pfizer as the pure powder and amphotericin B was from Sigma ( $80.0 \%$ purity).

Fungal strains. The antifungal activity of the essential oil of sample A was evaluated against yeasts and filamentous fungi: four clinical Candida strains isolated from recurrent cases of vulvovaginal and oral candidosis (Candida albicans D5, Candida albicans M1, Candida krusei H9 and Candida guilliermondii MAT23); three Candida type strains from the American Type Culture Collection (Candida albicans ATCC 10231, Candida tropicalis ATCC 13803 and Candida parapsilopsis ATCC 90018); one Cryptococcus neoformans type strain from the Colección Espanõla de Cultivos Tipo (Cryptococcus neoformans CECT 1078); one Aspergillus clinical strain isolated from bronchial secretions (Aspergillus flavus F44) and two Aspergillus type strains from the American Type Culture Collection (Aspergillus niger ATCC 16404 and Aspergillus fumigatus ATCC 46645); three dermatophyte clinical strains isolated from nails and skin (Epidermophyton floccosum FF9, Trichophyton mentagrophytes FF7 and Microsporum canis FF1) and four dermatophyte type strains from the Colección Espanõla de Cultivos Tipo (Trichophyton mentagrophytes var. interdigitale CECT 2958, Trichophyton rubrum CECT 2794 , Trichophyton verrucosum CECT 2992 and Microsporum gypseum CECT 2908). All strains were stored in Sabouraud dextrose broth with $20 \%$ glycerol at $-80{ }^{\circ} \mathrm{C}$ and subcultured on Sabouraud dextrose agar (SDA) or potato dextrose agar (PDA) before each test, to ensure optimal growth conditions and purity.

Antifungal activity. Broth macrodilution methods based on the Clinical and Laboratory Standards Institute (CLSI) reference protocols M27-A3 (CLSI, 2008a) and M38-A2 (CLSI, 2008b), for yeasts and filamentous fungi, respectively, were used to determine MICs of the essential oils and their major constituents. A macrodilution rather than a microdilution design was used to allow the use of glass test tubes, thus avoiding the interaction of the essential oil with the plastic polymer material of the 96-well microtitre plates. Briefly, inoculum suspensions were prepared at appropriate densities in RPMI 1640 broth (with L-glutamine, without bicarbonate, and with the $\mathrm{pH}$ indicator phenol red) from SDA or PDA cultures and distributed into $12 \times 75 \mathrm{~mm}$ glass test tubes. Inoculum densities were confirmed by viability counts on SDA. Serial twofold dilutions of the oil were prepared in DMSO and added to the cell suspensions in order to obtain test concentrations ranging from 0.08 to $20.0 \mu \mathrm{l} \mathrm{ml}^{-1}$ (final DMSO concentrations never exceeded $2 \%, \mathrm{v} / \mathrm{v})$. Oil-free growth controls, as well as sterility and DMSO control tubes, were also included. The test tubes were incubated aerobically at $35{ }^{\circ} \mathrm{C}$ for $48 \mathrm{~h} /$ $72 \mathrm{~h}$ (Candida and Aspergillus species/Cryptococcus neoformans) and at $30{ }^{\circ} \mathrm{C}$ for 7 days (dermatophytes). MIC values were determined as the lowest concentration of the oil causing full growth inhibition. Quality control was performed by testing fluconazole and amphotericin B with the reference strains Candida parapsilopsis ATCC 22019 and Candida krusei ATCC 6258 and the results were within the predetermined limits. To measure minimal lethal concentrations (MLCs), $20 \mu \mathrm{l}$ samples were taken from each negative tube plus the first tube showing growth (to serve as a growth control) after MIC reading to SDA plates and incubated at $35{ }^{\circ} \mathrm{C}$ for $48 \mathrm{~h} / 72 \mathrm{~h}$ (Candida and Aspergillus species/Cryptococcus neoformans) or at $30{ }^{\circ} \mathrm{C}$ for 7 days (dermatophytes). MLC values were determined as the lowest concentration of the oil causing fungal death. All experiments were performed in triplicate and repeated whenever the results of each triplicate did not agree. A range of values is presented when different results were obtained.

\section{Mechanism of action}

Germ tube inhibition assay. Cell suspensions from overnight SDA cultures of Candida albicans strains ATCC 10231, D5 and M1 were prepared in NYP medium [ $N$-acetylglucosamine (Sigma; $10^{-3} \mathrm{~mol}$ $\mathrm{1}^{-1}$ ), Yeast Nitrogen Base (Difco; $3.35 \mathrm{~g}^{-1}$ ), proline (Fluka; $10^{-3}$ mol $\left.1^{-1}\right)$ and $\left.\mathrm{NaCl}\left(4.5 \mathrm{~g} \mathrm{l}^{-1}\right), \mathrm{pH} 6.7 \pm 0.1\right]$ (Marichal et al., 1986) and adjusted to obtain a density of $1.0 \pm 0.2 \times 10^{6}$ c.f.u. $\mathrm{ml}^{-1}$. The essential oil was diluted in DMSO and added in $10 \mu \mathrm{l}$ volumes to $990 \mu \mathrm{l}$ of the yeast suspensions (final DMSO concentration of $1 \%, \mathrm{v} /$ $\mathrm{v}$ ), obtaining a series of subinhibitory concentrations (as low as 1/64 of the MIC). The samples were incubated for $3 \mathrm{~h}$ at $37{ }^{\circ} \mathrm{C}$ without agitation and 100 cells from each sample were then counted in a 
haemocytometer. The percentage of germ tubes was determined as the number of cells showing hyphae at least as long as the diameter of the blastospore. Cells showing a constriction at the point of connection of the hypha to the mother cell, typical for pseudohyphae, were excluded. The results are presented as means \pm standard deviation (SD) of three separate experiments.

Flow cytometry. Yeast suspensions were prepared in PBS solution with $2 \%(\mathrm{w} / \mathrm{v})$ D-glucose from overnight SDA cultures of Candida albicans ATCC 10231 at $35{ }^{\circ} \mathrm{C}$ and adjusted, using a haemocytometer, to a final density of $2.0 \pm 0.2 \times 10^{6}$ c.f.u. $\mathrm{ml}^{-1}$. Serial twofold dilutions of the essential oil (final concentrations of $0.64-10.0 \mu \mathrm{l} \mathrm{ml}^{-1}$ ) and a single solution of amphotericin B at $2 \mu \mathrm{g} \mathrm{ml}^{-1}$ (four times the respective MIC of $0.5 \mu \mathrm{g} \mathrm{ml}^{-1}$ ) in PBS with $2 \%(\mathrm{w} / \mathrm{v})$ D-glucose were added to the cell suspensions and the mixtures were incubated at $35{ }^{\circ} \mathrm{C}$ in a humid atmosphere without agitation for $30 \mathrm{~min}, 4 \mathrm{~h}$ or $24 \mathrm{~h}$. Drug-free control tubes were included in each experiment. After this period, the cells were washed in PBS and resuspended in $500 \mu 1$ PBS with $2 \%(\mathrm{w} / \mathrm{v})$ D-glucose for FUN-1 (Invitrogen) staining and PBS for propidium iodide (PI; Sigma) staining. Five microlitres of the FUN-1 and PI solutions in DMSO and PBS, respectively, were added to the cell suspensions to obtain final concentrations of $0.5 \mu \mathrm{M}$ FUN-

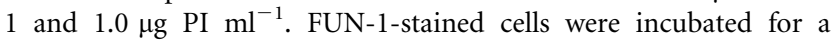
further $20 \mathrm{~min}$ at $35{ }^{\circ} \mathrm{C}$, away from incident light, while PI-stained samples were read after about $10 \mathrm{~min}$ at room temperature. Unstained cell suspensions were included as autofluorescence controls. Flow cytometry was performed using a FACSCalibur (Becton Dickinson Biosciences) flow cytometer with a $488 \mathrm{~nm}$ blue argon laser emitting at $15 \mathrm{~mW}$ and the results were analysed using CellQuest Pro Software (Becton Dickinson). Intrinsic parameters (forward and side scatter, for relative cell size and complexity analysis) and fluorescence in the FL2 channel (log yellow/orange fluorescence, bandpass filter $585 / 42 \mathrm{~nm}$ ) for FUN-1 and the FL3 channel (log red fluorescence, longpass filter $>650 \mathrm{~nm}$ ) for PI were acquired and recorded for a minimum of 7500 events per sample using logarithmic scales. Markers (M1) were adjusted to include a maximum of $5 \%$ of the cells in monoparametric histograms of the fluorescence intensity of control samples (see Fig. 1 for examples) and kept unchanged through the analysis of the remaining samples to quantify the percentages of cells showing altered fluorescence in comparison to the drug-free controls. Results are presented as means \pm SD of at least three replicate experiments.

\section{RESULTS AND DISCUSSION}

\section{Chemical compositions of the essential oils}

The essential oils were obtained in yields ranging from 0.7 to $1.2 \%(\mathrm{v} / \mathrm{w})$. A total of 51 compounds were identified, representing $93.2 \%$ (sample A) and $95.3 \%$ (sample B) of the total volatile oils. The oils were characterized by high contents of oxygen-containing monoterpenes (69.5 and $75.7 \%$ ), followed by monoterpene hydrocarbons (17.1 and $15.5 \%)$. The main constituents of the oils were 1,8 -cineole (34.5\% and $42.2 \%)$, camphor (13.4\%), $\alpha$-pinene $(9.0 \%)$ and linalool (7.9 and $6.7 \%)$. Sesquiterpenic compounds attained only 4.8 and $2.3 \%$.

In a previous study carried out by Garcia-Vallejo (1992), some individual samples of $L$. viridis from the south of Portugal and Spain were analysed. The chemical composition of these samples was very similar to that of our collective samples, 1,8-cineole being the major component in all samples. This fact points to a very high homogeneity in the composition of the essential oils of $L$. viridis from Portugal and Spain.

\section{Antifungal activity of the essential oils}

The essential oil was used to evaluate the antifungal activity against several pathogenic strains involved in human diseases. Various degrees of inhibition were registered against all the fungi tested (Table 1).

The highest antifungal activity was observed against dermatophyte strains and Cryptococcus neoformans, with
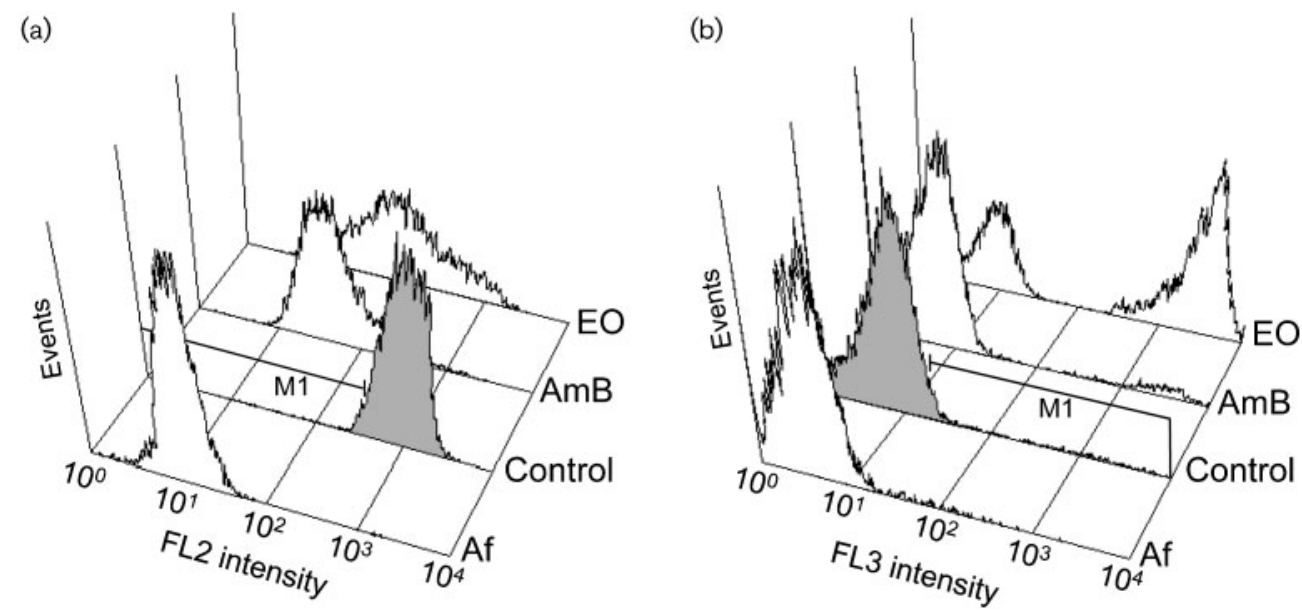

Fig. 1. Flow cytometry histograms showing fluorescence intensity versus number of events (Candida albicans ATCC 10231 cells) in relative units. (a) Orange fluorescence (FL2 channel) intensity of samples stained with FUN-1. (b) Red fluorescence (FL3 channel) intensity of samples stained with PI. Af, Autofluorescence of unstained cells; control, untreated cells; AmB, cells treated with amphotericin $\mathrm{B}$ at $2.0 \mu \mathrm{g} \mathrm{ml}^{-1}$; EO, cells treated with the essential oil of $L$. viridis at $10.0 \mu \mathrm{ml}^{-1}$. 
Table 1. Antifungal activity (MIC and MLC) of the essential oil of Lavandula viridis (sample A) for Candida, dermatophyte and Aspergillus strains

Results were obtained from three independent experiments performed in duplicate. When different MIC values were obtained, a range of values is presented. NT, Not tested.

\begin{tabular}{|c|c|c|c|c|c|c|c|c|c|c|c|c|c|c|}
\hline \multirow[t]{2}{*}{ Strain } & \multicolumn{2}{|c|}{ L. viridis } & \multicolumn{2}{|c|}{ 1,8-Cineole } & \multicolumn{2}{|c|}{ Camphor } & \multicolumn{2}{|c|}{$\alpha$-Pinene } & \multicolumn{2}{|c|}{ Linalool } & \multicolumn{2}{|c|}{ Fluconazole } & \multicolumn{2}{|c|}{$\begin{array}{c}\text { Amphotericin } \\
\text { B }\end{array}$} \\
\hline & $\mathrm{MIC}^{\star}$ & $\mathrm{MLC}^{*}$ & $\mathrm{MIC}^{*}$ & MLC $^{\star}$ & $\mathrm{MIC}^{*}$ & MLC $^{*}$ & $\mathrm{MIC}^{*}$ & $\operatorname{MLC}^{*}$ & $\mathrm{MIC}^{*}$ & MLC $^{*}$ & $\mathrm{MIC} \dagger$ & MLC $\dagger$ & $\mathrm{MIC} \dagger$ & MLC $\dagger$ \\
\hline Candida albicans ATCC 10231 & 2.5 & 2.5 & 10 & 10 & $>20$ & $>20$ & $0.64-1.25$ & $0.64-1.25$ & 5 & 5 & 1 & $>128$ & NT & NT \\
\hline Candida albicans D5 & 1.25 & 1.25 & $5-10$ & $5-10$ & $\geqslant 20$ & $>20$ & 0.32 & 0.32 & 5 & 5 & 64 & $>128$ & NT & NT \\
\hline Candida albicans $\mathrm{M} 1$ & 2.5 & 2.5 & 10 & 10 & $>20$ & $>20$ & $0.64-1.25$ & $0.64-1.25$ & 5 & $5-10$ & 2 & 128 & NT & NT \\
\hline Candida tropicalis ATCC 13803 & $1.25-2.5$ & $1.25-2.5$ & 20 & 20 & $>20$ & $>20$ & 1.25 & $1.25-2.5$ & 5 & 5 & 4 & $>128$ & NT & NT \\
\hline Candida krusei $\mathrm{H} 9$ & $1.25-2.5$ & $1.25-2.5$ & 10 & 10 & $>20$ & $>20$ & $0.16-0.32$ & 0.32 & 10 & 10 & 64 & $64-128$ & NT & NT \\
\hline Candida guilliermondii MAT23 & $0.64-1.25$ & $0.64-1.25$ & 10 & 10 & $>20$ & $>20$ & 0.64 & 0.64 & 5 & 10 & 8 & 8 & NT & NT \\
\hline $\begin{array}{l}\text { Candida parapsilopsis ATCC } \\
90018\end{array}$ & 1.25 & 1.25 & 10 & 10 & $>20$ & $>20$ & 0.32 & 0.32 & 10 & 10 & $<1$ & $<1$ & NT & NT \\
\hline $\begin{array}{l}\text { Cryptococcus neoformans CECT } \\
1078\end{array}$ & 0.64 & 0.64 & $5-10$ & 10 & $>20$ & $>20$ & 0.08 & 0.32 & 5 & 5 & 16 & 128 & NT & NT \\
\hline $\begin{array}{l}\text { Trichophyton mentagrophytes } \\
\text { FF7 }\end{array}$ & $0.32-0.64$ & 0.64 & 5 & 5 & $>20$ & $>20$ & 0.32 & $0.32-0.64$ & 1.25 & 2.5 & $16-32$ & $32-64$ & NT & NT \\
\hline $\begin{array}{l}\text { Trichophyton mentagrophytes } \\
\text { var. interdigitale CECT } 2958\end{array}$ & $0.32-0.64$ & 0.64 & $10-20$ & $10-\geqslant 20$ & $>20$ & $>20$ & 0.32 & 0.32 & 2.5 & $2.5-5$ & 128 & $\geqslant 128$ & NT & NT \\
\hline $\begin{array}{l}\text { Trichophyton rubrum CECT } \\
2794\end{array}$ & 0.32 & 0.32 & $2.5-5$ & 5 & $>20$ & $>20$ & 0.08 & 0.08 & 1.25 & $1.25-2.5$ & 16 & 64 & NT & NT \\
\hline $\begin{array}{l}\text { Trichophyton verrucosum CECT } \\
2992\end{array}$ & 0.32 & $0.32-0.64$ & 10 & 10 & $>20$ & $>20$ & 1.25 & 1.25 & $1.25-2.5$ & $1.25-2.5$ & $>128$ & $>128$ & NT & NT \\
\hline Microsporum canis $\mathrm{FF} 1$ & 0.32 & 0.32 & 5 & 5 & $>20$ & $>20$ & 0.16 & $0.16-0.32$ & 2.5 & 2.5 & 128 & 128 & NT & NT \\
\hline $\begin{array}{l}\text { Microsporum gypseum CECT } \\
2905\end{array}$ & 0.64 & 0.64 & $5-10$ & 5 & $>20$ & $>20$ & 0.16 & 0.16 & $1.25-2.5$ & 2.5 & 128 & $>128$ & NT & NT \\
\hline Epidermophyton floccosum $\mathrm{FF9}$ & 0.32 & 0.32 & 5 & 5 & $>20$ & $>20$ & 0.16 & 0.16 & $1.25-2.5$ & 2.5 & 16 & 16 & NT & NT \\
\hline Aspergillus niger ATCC16404 & 2.5 & 20 & 10 & $>20$ & $>20$ & $>20$ & 2.5 & 5 & 5 & $\geqslant 20$ & NT & NT & $1-2$ & 4 \\
\hline $\begin{array}{l}\text { Aspergillus fumigatus ATCC } \\
46645\end{array}$ & 2.5 & $5-10$ & 10 & $10-20$ & 20 & $>20$ & 1.25 & $1.25-2.5$ & 2.5 & 20 & NT & NT & 2 & 4 \\
\hline Aspergillus flavus F44 & 5 & $10-20$ & 20 & 20 & 20 & 20 & 1.25 & 1.25 & 10 & $\geqslant 20$ & NT & NT & 2 & 8 \\
\hline
\end{tabular}

${ }^{\star} \mathrm{MIC}$ and MLC were determined by a macrodilution method and expressed in $\mu \mathrm{l} \mathrm{ml}^{-1}(\mathrm{v} / \mathrm{v})$.

$\dagger \mathrm{MIC}$ and MLC were determined by a macrodilution method and expressed in $\mu \mathrm{g} \mathrm{ml}^{-1}(\mathrm{w} / \mathrm{v})$. 
MIC and MLC values ranging from 0.32 to $0.64 \mu \mathrm{ml}^{-1}$. For Candida strains, MIC and MLC values ranged from 0.64 to $2.5 \mu \mathrm{l} \mathrm{ml}^{-1}$. The oil was less effective against Aspergillus strains (Table 1). The higher susceptibility of dermatophytes has also been reported for other essential oils (Salgueiro et al., 2004; Pinto et al., 2006, 2009; Zuzarte et al., 2009).

For most of the dermatophytes, Cryptococcus neoformans and Candida strains, the MIC was equivalent to the MLC, indicating a clear fungicidal effect of $L$. viridis essential oil.

The major constituents of the oil (1,8-cineole, camphor, $\alpha$ pinene and linalool) were also assayed individually for their antifungal activity. 1,8-Cineole and camphor displayed the lowest antifungal activity against all strains but $\alpha$-pinene proved to be a very active compound, particularly against dermatophyte strains (Table 1). Since the essential oils are complex mixtures of several compounds, it is difficult to attribute their biological activity to a particular constituent. Usually, major compounds are the ones responsible for the antifungal activity of the essential oils. However, some studies show that minor components may have a crucial role in the biological activity of the oils (Koroch et al., 2007). Our results seem to indicate that the activity of $L$. viridis essential oil is mainly due to the presence of $\alpha$ pinene in the oil.

\section{Mechanism of action of the essential oil}

The essential oil was also found to inhibit filamentation in the tested Candida albicans strains at concentrations of $0.08-0.16 \mu \mathrm{l} \mathrm{ml}^{-1}$, well below the corresponding MICs (Table 2). This marked difference between MICs and filamentation-inhibiting concentrations seems to suggest that different mechanisms may be responsible for these two biological activities. This finding is particularly relevant considering the fact that filamentation has long been shown to be essential for virulence in Candida albicans (Mitchell, 1998). In fact, inhibition of the dimorphic transition alone has been suggested to be sufficient to treat disseminated candidosis, thus proving to be a good target mechanism in the development of novel antifungal agents (Saville et al., 2006). Additionally, flow cytometry analyses after FUN-1 staining have revealed a dose-dependent inhibition of cell metabolism after short incubation periods with the oil at concentrations starting from the respective MIC (Fig. 2). The dye FUN-1 freely permeates fungal plasma membranes into the cell and is distributed in the cytoplasm as a bright diffuse green/yellow stain. In normal fungal cells, the dye is metabolized into orange/red cylindrical intravacuolar structures. However, in cells with impaired metabolism, this change does not occur and FUN-1 remains in the cytoplasm in a diffuse pattern, indicating a disorder in cell metabolism (Millard et al., 1997). This change was detected by a reduction of orange fluorescence (FL2 channel) in cells exposed to the essential oil in comparison to untreated controls (Figs 1 and 2). To observe PI staining of the test cells, on the other hand, a $4 \mathrm{~h}$ incubation with a concentration of the oil at least two $\log _{2}$ dilutions above the MIC was required (Fig. 2). The nucleic acid binding fluorescent probe PI penetrates only dead cells showing severe membrane lesions (Pina-Vaz et al., 2001). The observed asymmetry between metabolic inhibition and cell death shows that cells clearly become metabolically inactive in the presence of the essential oil of $L$. viridis before it leads to cell death, thus appearing to exclude a potential mechanism of antifungal action relying on primary leakage of cytoplasmic contents due to direct damage to cell membranes. It is worth pointing out that under the same experimental conditions, the reference fungicidal drug amphotericin B tested at a concentration two $\log _{2}$ dilutions above the respective MIC did not lead to PI staining (Fig. 2). After $24 \mathrm{~h}$, however, over $90 \%$ of the cells presented positive PI staining with amphotericin B treatment (data not shown).

The mechanism of action of essential oils remains somewhat controversial. While some studies suggest that the compounds may penetrate the micro-organism and react with active sites of enzymes and/or interfere with cellular metabolism, most evidence supports direct disruption of cellular membranes and concentration-dependent pro-oxidant cytotoxic effects (Bakkali et al., 2008). Concerning antifungal activity specifically, the mechanism of action of the oils seems to involve penetration through cell walls and direct damage to both cytoplasmic and mitochondrial membranes (Bakkali et al., 2008). This leads to changes in permeability leading to leakage and ultimately resulting in cell death (Bakkali et al., 2008). Bearing this knowledge in mind, the present results for the

Table 2. Percentage of germ tubes after treatment of three Candida albicans strains with subinhibitory concentrations of the essential oil of $L$. viridis for $3 \mathrm{~h}$ in a filamentation-inducing medium at $37^{\circ} \mathrm{C}$

Results are presented as mean $( \pm \mathrm{SD})$ values of three independent experiments. Concentration is in $\mu \mathrm{ml}^{-1}(\mathrm{v} / \mathrm{v})$.

\begin{tabular}{|lclll|}
\hline Strain & MIC/16 (concn) & MIC/32 (concn) & MIC/64 (concn) & Control $^{*}$ \\
\hline C. albicans ATCC 10231 & $6.7 \pm 6.4(0.16)$ & $54.0 \pm 5.6(0.08)$ & $89.7 \pm 2.1(0.04)$ & $94.0 \pm 5.2$ \\
C. albicans D5 & $0.0 \pm 0.0(0.08)$ & $47.5 \pm 10.6(0.04)$ & $66.0 \pm 5.7(0.02)$ & $86.8 \pm 9.4$ \\
C. albicans M1 & $0.3 \pm 0.6(0.16)$ & $42.7 \pm 10.5(0.08)$ & $75.0 \pm 4.2(0.04)$ & $87.5 \pm 6.6$ \\
\hline
\end{tabular}

${ }^{\star}$ Untreated samples including the solvent ( $1 \%$ DMSO) only. 


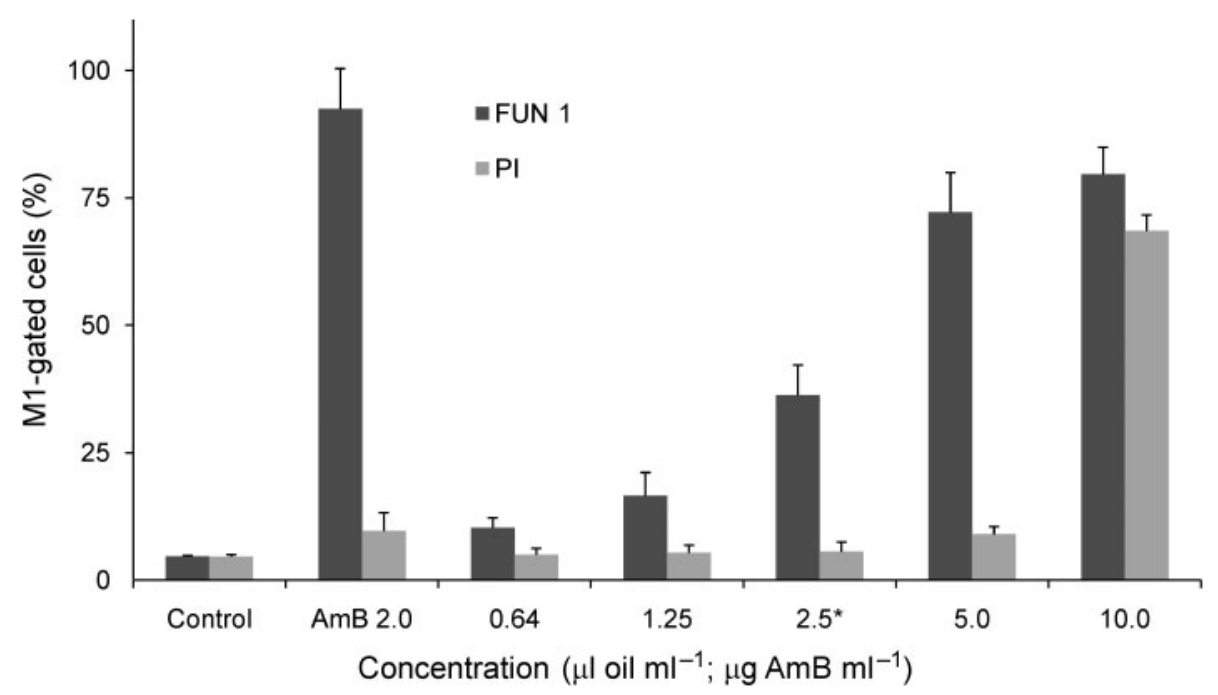

Fig. 2. Percentage (and SD) of M1-gated Candida albicans ATCC 10231 cells, analysed by flow cytometry, after treatments with different concentrations of the essential oil of $L$. viridis in comparison with amphotericin $B(A m B)$ and an untreated control. Cells were treated with the compounds for 30 min for staining with FUN-1 and $4 \mathrm{~h}$ for staining with PI. *MIC of the essential oil.

specific case of Candida albicans treated with the essential oil of $L$. viridis are consistent with a mechanism of action starting from damage to mitochondrial membranes, considering the rapid metabolical arrest appearing earlier and in the presence of lower concentrations of the essential oil than those required to cause cell death. In such a scenario, changes in mitochondrial permeability would disturb electron flow in the electron transport chain, generating free radicals that proceed to damage essential biomolecules (including lipids, proteins and nucleic acids). Given a high enough concentration and/or exposure time, the oil may eventually lead to disruption of cytoplasmic membranes and cell death. Further data are now required to definitively confirm these speculations, however.

The wide-spectrum antifungal activity and high potency of the oil of $L$. viridis support further investigations into the development of this essential oil for clinical use in the management of superficial and/or mucosal fungal infections.

\section{ACKNOWLEDGEMENTS}

This work was supported by CEF/POCI2010/FEDER and by the Portuguese Foundation for Science and Technology (FCT) through a $\mathrm{PhD}$ fellowship to M.R.Z. (SFRH/BD/40218/2007) and a postdoctoral fellowship to L. V.-S. (SFRH/BPD/29112/2006).

\section{REFERENCES}

Adams, R. P. (1995). Identification of Essential Oil Components by Gas Chromatography/Mass Spectroscopy. Carol Stream, IL: Allured Publishing Corporation.

Angioni, A., Barra, A., Coroneo, V., Dessi, S. \& Cabras, P. (2006). Chemical composition, seasonal variability, and antifungal activity of Lavandula stoechas L. ssp. stoechas essential oils from stem/ leaves and flowers. J Agric Food Chem 54, 4364-4370.

Bakkali, F., Averbeck, S., Averbeck, D. \& Idaomar, M. (2008). Biological effects of essential oils - a review. Food Chem Toxicol 46, 446-475.

Cavaleiro, C., Salgueiro, L. R., Miguel, M. G. \& Proença da Cunha, A. (2004). Analysis by gas chromatography-mass spectrometry of the volatile components of Teucrium lusitanicum and Teucrium algarbiensis. J Chromatogr A 1033, 187-190.

Cavaleiro, C., Pinto, E., Gonçalves, M. J. \& Salgueiro, L. R. (2006). Antifungal activity of Juniperus essential oils against dermatophyte, Aspergillus and Candida strains. J Appl Microbiol 100, 1333-1338.

Cavanagh, H. M. A. \& Wilkinson, J. M. (2002). Biological activities of lavender essential oil. Phytother Res 16, 301-308.

CLSI (2008a). Reference Method for Broth Dilution Antifungal Susceptibility Testing of Yeasts; Approved Standard, 3rd edn. M27A3. Wayne, PA: Clinical and Laboratory Standards Institute.

CLSI (2008b). Reference Method for Broth Dilution Antifungal Susceptibility Testing of Filamentous Fungi; Approved Standard, 3rd edn. M38-A2. Wayne, PA: Clinical and Laboratory Standards Institute.

Council of Europe (1997). European Pharmacopoeia, 3rd edn. Strasbourg: Council of Europe.

Dadalioğlu, I. \& Evrendilek, G. A. (2004). Chemical compositions and antibacterial effects of essential oils of Turkish oregano (Origanum minutiflorum), bay laurel (Laurus nobilis), Spanish lavender (Lavandula stoechas L.), and fennel (Foeniculum vulgare) on common foodborne pathogens. J Agric Food Chem 52, 8255-8260.

Ferris, D. G., Nyirjesy, P., Sobel, J. D., Soper, D., Pavletic, A. \& Litaker, M. S. (2002). Over-the-counter antifungal drug misuse associated with patient-diagnosed vulvovaginal candidiasis. Obstet Gynecol 99, 419-425.

Garcia-Vallejo, M. I. (1992). Aceites esenciales de las Lavandulas Ibericas - Ensayo de la quimiotaxonomia. Tesis Doctoral, Universidad Complutense de Madrid.

González-Coloma, A., Martín-Benito, D., Mohamed, N., Garcia-Vallejo, M. C. \& Soria, A. C. (2006). Antifeedant effects and 
chemical composition of essential oils from different populations of Lavandula luisieri L. Biochem Syst Ecol 34, 609-616.

Joulain, D. \& König, W. A. (1998). The Atlas of Spectral Data of Sesquiterpene Hydrocarbons. Hamburg: E. B. Verlag.

Koroch, A. R., Juliani, H. R. \& Zygadlo, J. A. (2007). Bioactivity of essential oils and their components. In Flavours and Fragrances. Chemistry, Bioprocessing and Sustainability, pp. 87-115. Edited by R. G. Berger. Berlin, Heidelberg: Springer-Verlag.

Marichal, P., Gorrens, J., Van Cutsem, J. \& Vanden Bossche, H. (1986). Culture media for the study of the effects of azole derivatives on germ tube formation and hyphal growth of C. albicans. Mykosen 29, 76-81.

Matos, F., Miguel, M. G., Duarte, J., Venâncio, F., Moiteiro, C., Correia, A. I. D., Figueiredo, A. C., Barroso, J. G. \& Pedro, L. G. (2009). Antioxidant capacity of the essential oils from Lavandula luisieri, L. stoechas subsp. lusitanica, L. stoechas subsp. lusitanica $\mathrm{x} L$. luisieri and L. viridis grown in Algarve (Portugal). JEOR 21, 327-336.

Millard, P. J., Roth, B. L., Thi, H. P., Yue, S. T. \& Haugland, R. P. (1997). Development of the FUN-1 family of fluorescent probes for vacuole labeling and viability testing of yeasts. Appl Environ Microbiol 63, 2897-2905.

Mitchell, A. P. (1998). Dimorphism and virulence in Candida albicans. Curr Opin Microbiol 1, 687-692.

Moon, T., Wilkinson, J. M. \& Cavanagh, H. M. A. (2006). Antibacterial activity of essential oils, hydrosols and plant extracts from Australian grown Lavandula spp. Int J Aromatherapy 16, 9-14.

Pérez-Parra, A., Muñoz, P., Guinea, J., Martín-Rabadán, P., Guembe, M. \& Bouza, E. (2009). Is Candida colonization of central vascular catheters in non-candidemic, non-neutropenic patients an indication for antifungals? Intensive Care Med 35, 707-712.

Perrucci, S., Macchioni, G., Cioni, P. C., Flamini, G., Morelli, I. \& Taccini, F. (1996). The activity of volatile compounds from Lavandula angustifolia against Psoroptes cuniculi. Phytother Res 10, 5-8.

Pfaller, M. A., Pappas, P. G. \& Wingard, J. R. (2006). Invasive fungal pathogens: current epidemiological trends. Clin Infect Dis 43, S3-S14.
Pina-Vaz, C., Sansonetty, F., Rodrigues, A. G., Costa-Oliveira, S., Tavares, C. \& Martinez-de-Oliveira, J. (2001). Cytometric approach for a rapid evaluation of susceptibility of Candida strains to antifungals. Clin Microbiol Infect 7, 609-618.

Pina-Vaz, C., Gonçalves Rodrigues, A., Pinto, E., Costa-de-Oliveira, S., Tavares, C., Salgueiro, L. R., Cavaleiro, C., Gonçalves, M. J. \& Martinez-de-Oliveira, J. (2004). Antifungal actvity of Thymus oils and their major compounds. J Eur Acad Dermatol 18, 73-78.

Pinto, E., Pina-Vaz, C., Salgueiro, L., Gonçalves, M. J., Costa-deOliveira, S., Cavaleiro, C., Palmeira, A., Rodrigues, A. \& Martinez-deOliveira, J. (2006). Antifungal activity of the essential oil of Thymus pulegioides on Candida, Aspergillus and dermatophyte species. J Med Microbiol 55, 1367-1373.

Pinto, E., Vale-Silva, L., Cavaleiro, C. \& Salgueiro, L. (2009). Antifungal activity of the clove essential oil from Syzygium aromaticum on Candida, Aspergillus and dermatophyte species. J Med Microbiol 58, 1454-1462.

Ríos, J. L. \& Recio, M. C. (2005). Medicinal plants and antimicrobial activity. J Ethnopharmacol 100, 80-84.

Romani, L. (2007). Immunity to fungi. In New Insights in Medical Mycology, pp. 1-18. Edited by K. Kavanagh. Dordrecht: Springer.

Salgueiro, L. R., Pinto, E., Gonçalves, M. J., Pina-Vaz, C., Cavaleiro, C., Rodrigues, A. G., Palmeira, A., Tavares, C., Costa-de-Oliveira, S. \& Martinez-de-Oliveira, J. (2004). Chemical composition and antifungal activity of the essential oil of Thymbra capitata. Planta Med 70, 572-575.

Saville, S. P., Lazzell, A. L., Bryant, A. P., Fretzen, A., Monreal, A., Solberg, E. O., Monteagudo, C., Lopez-Ribot, J. L. \& Milne, G. T. (2006). Inhibition of filamentation can be used to treat disseminated candidiasis. Antimicrob Agents Chemother 50, 3312-3316.

Upson, T. M. \& Andrews, S. (2004). The Genus Lavandula. Kew, London: The Royal Botanical Gardens.

Zuzarte, M., Gonçalves, M. J., Cavaleiro, C., Dinis, A. M., Canhoto, J. M. \& Salgueiro, L. R. (2009). Chemical composition and antifungal activity of the essential oils of Lavandula pedunculata (Miller) Cav. Chem Biodivers 6, 1283-1292. 